\title{
Enhancement of Permit-to-Work System Toward Safety Risk Assessment Supporting by GPS, Face Recognition and IoT:
} Research on Company XYZ

\author{
Hery Purwoko, Suryadiputra Liawatimena
}

\begin{abstract}
An increase in the number accident related to the permit to work (PTW) has overwhelming, as in the past, the explosion and fire accident which occurred in the Piper Alpha offshore oil and gas platform in 1988, have killed 167 workers, and also the lack of an issued permit for the actual job, was one of the reasons for the Hickson and Welch accident in 1992 was attributed mainly to human error including deficiencies in the permit to work (PTW) system. Moreover, at company XYZ (2015) because of PTW risk assessment is not adequately conducted onsite, and the technician neglect the potential hazard associated with his work, his experience a lost-time injury (LTI). Therefore, an enhancement of PTW by using GPS, Bio Metric (Face recognition) and IoT to make sure the worker doing PTW properly and make the risk assessment (process with Natural language) onsite before commencing the non-routine job is the essential safety requirement. This research is aim to enhance the existing conventional permit to work system (PTW) into ePTW, (Electronic Permit to Work) information system focus on creating Risk Assessment support by implementing a mobile cloud computing using GPS and Face recognition to verify that the workers are on-premises to do proper PTW and smart lock (IoT) to ensure the isolation done properly, all these features is to help reduce the probability of human errors or non-conformance. PTW enhancement evaluation is using Analytic Maturity Assessment Model to analyze whether the established system in the company or organization is mature enough and valuable of the safety processes and gives positive impacts to the company its overall business performance through safety best practice.
\end{abstract}

Keywords : Permit-to-Work, PTW, GPS, Lock Out Tag Out, Face recognition, IoT, Hazard.

\section{INTRODUCTION}

In the last couple of decades permit to work has become profound as safety best practice to plan a safety assessment prior to doing a job in the workplace. Here are some of the

Revised Manuscript Received on March 04, 2020.

* Correspondence Author

Hery Purwoko*, Computer Science Department BINUS Graduate Program-Master of Computer Science Bina Nusantara University, Jakarta, Indonesia 11480, hery.purwoko@binus.ac.id / heripurwoko@gmail.com

Suryadiputra Liawatimena1,2, 1) Computer Science Department, BINUS Graduate Program - Master of Computer Science, Bina Nusantara University, Jakarta, Indonesia 11480 2) Computer Engineering Department Faculty of Engineering Bina Nusantara University, Jakarta, Indonesia 11480, suryadi@binus.edu / s.liawatimena.id@ieee.org

(C) The Authors. Published by Blue Eyes Intelligence Engineering and Sciences Publication (BEIESP). This is an open access article under the CC BY-NC-ND license (http://creativecommons.org/licenses/by-nc-nd/4.0/) problem in the protection of workplace workers according to the safety report in Korea Occupational Safety and Health Agency stated that about $37 \%$ or 49 of the 130 serious accident were associated with maintenance and safety work procedure [1], in chemical plant in Iran study shows human errors contributes approximately $50.7 \%$ of safety work procedure (PTW) [2], in construction site about $90 \%$ of workplace injuries happened because of unsafe work practice and behaviors [3]. That's why this research is very important to reduce the accident or incident in company XYZ and find a digitalized solution to improve the permit to work system. In reality people tend to do short cut, and if they get lucky some of them will get away, but luck is not an option, do your job as per the procedure, and safe manner are very important point and saving one life is like saving the entire mankind, that's why in this research the development of many precautions is required such face recognition and GPS to make sure the worker is onsite, to review the potential hazard in premises and IoT (smart lock) is to be used for isolation, moreover as shown in Fig.1 the root cause [4] of the accident through five why analysis [5], after investigation, it because not doing proper risk assessment is the main root cause of the injury. Hence in this research, is focusing on how to create proper risk assessment with the help of natural language processing (NLP), so that as per [2] human error can be reduced in the PTW issuance process and as support using face recognition, GPS and IoT.

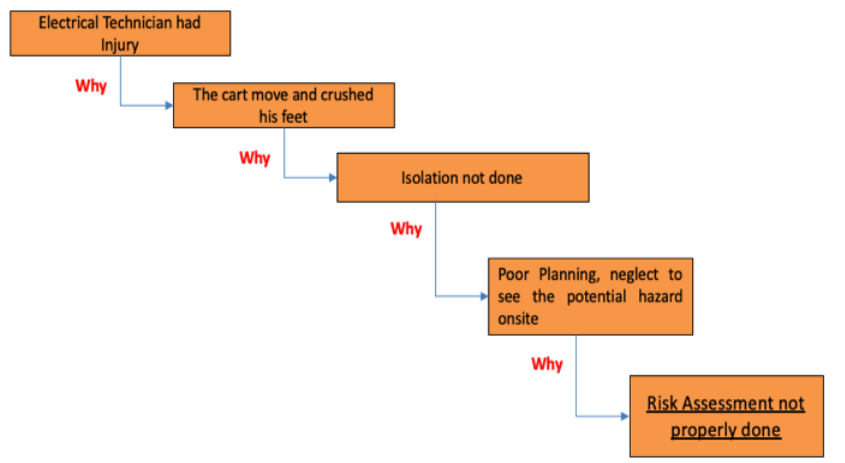

Fig.1. Five Why Analysis to find the accident root cause

In this work, we motivate safety culture in company XYZ by using information and communication technology by developing an electronic permit to work system (ePTW) with the following contribution

Published By:

Blue Eyes Intelligence Engineering \& Sciences Publication 


\section{Enhancement of Permit-to-Work System Toward Safety Risk Assessment Supporting by GPS, Face Recognition and IoT:Research on Company XYZ}

- Prototyping ePTW supports face recognition and GPS system, to make sure the worker on work premises.

- Prototyping Smart Lock Out Tag Out as an additional precaution to prevent equipment from running by isolate it.

- Using an analytic maturity assessment model to evaluate the enhancement of PTW is as per company XYZ requirement.

The above contribution will form an information system that will be discussed in another chapters, the aim of this system should reduce procedure deviation of PTW and the system should cope with legal requirement [6] and also introduce new way of safety practice on how mobile safety application program give an advantage in enhancing safety procedure (PTW) as well as an improving the company's image and overall safety performance (reduce accident and incident).

\section{RELATED WORKS}

The complex and dynamic of permit to work toward safety risk assessment has interest many of researcher in many field (chemical, construction, etc.) from seeking on the root cause of failed PTW, into build a tool to help worker in workplace to have better understanding the hazard associated with the equipment, mitigate the hazards and plan their job safely.

In [1] embedded the JSA(document of Job Safety Analysis) into PTW information system was introduce, the deduction of hazards and responded pre-risk and consequences presentation scheme was more effective, with a final Survey effectiveness of the information system: for the derivability of hazards, $\mathbf{7 8 \%}$ of the responder answered the effectiveness of the new system was very high and $22 \%$ responded that it was high. [7] emphasize in mining industry despite of important contributor of Australian society the safety record was poor and PTW as safety approach is lack of conceptual and theoretical model. The essence of safe practice, from the point of view of those actually performing work, was not about having in-depth knowledge of, or compliance to, prescribed procedures; but the ability to perceive and distinguish between different types of situations and act accordingly when there was no clear path to follow, by modified prescriptions - repetitions - distinctions descriptions (M-PRDD) model is a useful and pragmatic model for examining whether PTW systems enhance or hinder resilient engineering as a safety management strategy. Another enhancement in PTW, [8] develop work permit information system to eliminate paperwork and found effectively to reduce injury in the shipyard. In [9] thesis, it's concluded an averagely $63 \%$ of respondents are not sure either the current PTW system helps to prevent hazard on the site effectively. This possibly due to the design of the system itself. One respondent raised that electronic approval will not achieve the safety objectives if it is approved by those who is not on the site. Supposedly, PTW and site verification prior work commencement should be done by personnel available at site as they directly observe the potential hazard. It also stated electronic permit-to-work system provide work order integration, risk assessment, isolation of hazardous activities, competency management, lesson learned and continual improvement, however, it does not help in improving the compliance of PTW.
Moreover [2] and [10] research to determine the cause of PTW failure, [2] using Standardized Plant Analysis Risk-Human (SPAR-H) reliability Analysis for estimation human error probability. Quantify potential human errors probabilities in the PTW system. The Research shows between worker has a different human error (Safety officer 0.002, SPV 0.0164, Site Man one 0.185, Site Man two 0.169) it happened because of lack of experience, training and procedure. And [10] using Data Mining to identify the main factor of PTW related accidents, which are classified under organization, human factors, communication, competency, procedure, etc. From their research the most contributor factor of PTW failure as per the following: Human Factor $\mathbf{1 6 . 2 \%}$, Communication $16.2 \%$ and procedure $16.2 \%$. Supervision $13.2 \%$, Tools \& Equipment $13.2 \%$, Competency 13.2\% and Organization 11.8\%.

In construction field [11] using 2D construction drawings and text data, such as method statements, and discussions on-site as safety hazard identification case study tool, [3] using Ontology-based construction safety knowledge, toward automated safety planning for job hazard analysis using Building Information Modeling (BIM). Simulation of safety and visualization of model through BIM with safety resources, make worker able to plan for safety at front end and share the findings onsite. And [12] conclude the adoption BIM 4D modeling for site health and safety management currently remain low.

Another method on safety assessment [13] introduce Weight allocation of an expert is revised by cluster analysis (to quantify data), to improve the rationality. Next, the fuzzy membership function is constructed, and fuzzy neural network safety assessment model is established, After the 326 times of studies, the fuzzy neural network of bridge crane safety assessment was completed. To verify the network, they enter another five sets of evaluation samples are taken as verification samples into the network. Neural network output is compared with the results of the expert evaluation and they are identical.

In this paper we would like introduce another method in PTW to create risk/safety assessment refer from hazard dataset, JSP and hazard repository from related equipment and supported using GPS, face recognition to verify that the worker is onsite to review present hazards and using smart lock (LOTO) as additional safety feature to ensure the isolation done properly, all these features is to help reduce the probability of human errors or non-conformance.

\section{RESEARCH FRAMEWORK/METHODOLOGY}

This paper aims to have the best practice of PTW in company XYZ therefore the methodology research framework of this thesis is using approach of [1] with some of the enhancement ePTW (See Fig.2). Where's the ePTW is embedded with JSP to have more references on how to get the job done in safe manners as per procedure, while the JSP itself is created a base on each related equipment which every equipment has its own related hazards. The Dataset where build base on input from past accident or incident record and pre /post

Published By: 
hazard assessment of ePTW to have a better understanding what are the related hazard while doing the job, this will become the hazard references for future works on same equipment or location. The IoT make sure that the stakeholder that take parts on the job is legitimate and on premises to have better views of present hazard.

The premises collection using the GPS will be trigger by the following sequence:

- $\quad$ ePTW Creation location (Issuer Face recognition)

- Site visit on Hazard Identification or Risk Assessment

- Receiver acknowledge the ePTW (Receiver Face recognition)

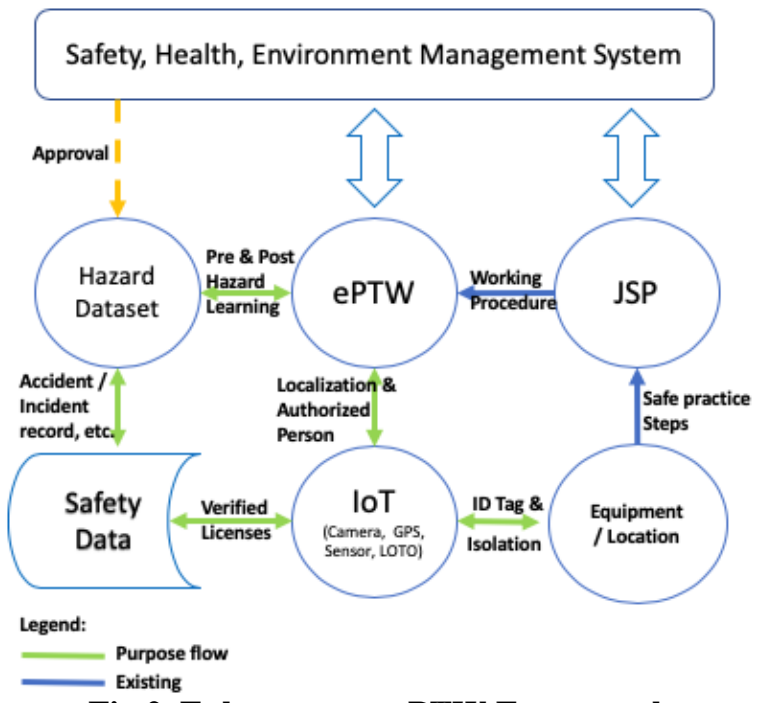

Fig.2. Enhancement ePTW Framework.

Safety, Health, Environment Management System (SHE-MS) are the umbrella (Code of Practice) for the framework to be implemented on company XYZ.

\section{THEORY AND METHODS}

Gap assessment is introduced to know our current situation of PTW as per [1] survey audit conducted by auditing ten stakeholder using two aspect of audit (Safety \& Work Performance) moreover as per [14], [15] Analytic Maturity Assessment Model is introduce to analyze whether the established system in the company or organization is mature enough and valuable of business access processes on certain aspect of the organization toward systematically organized on the way they do business, this model is to analyze and evaluate the current status and future development of ePTW. Once the system is done, the researcher is be able to evaluate the research result base on this model.

To capture, analyze and evaluate appropriate PTW model, Gartner Analytic Maturity Assessment Model [16] (See Fig.3) is used as per below:

What happened? One of the Electricians had an accident due to his feed was crushed by an anode.

Why did it happen? One of the root causes is equipment isolation failure which not determine on PTW because the worker did not do risk assessment onsite and did do the risk assessment properly. To make sure the worker in the premises can be solve by using [17] and [18] GPS utilization for attendance management and work performance management. Collect location (outdoor) information, give a complete overview of employee whereabout, moreover [19] using fiducial detection and orientation from a database than using CCTV camera for indoor navigation using pedestrian dead reckoning algorithm, the overall appreciation was positive (average score of $\mathbf{7 9 . 7 \%}$ ). The navigation was viewed as effective (73.9\%). Another worker identification method can be use also as face recognition [20] using Principle Component Analysis (PCA) which is a statistic technique that transforms a multivariate dataset of intercorrelated variables into a dataset of new uncorrelated linear combinations of the original variables. It also introduces a framework of multimodal 2D and 3D face recognition which utilize facial information at the enrollment and image construction. On the other hand [21] using convolutional neural network (CNN) performance have been improve greatly through the year from $97 \%$ to $99 \%$, they proposed a Max-Feature-Map operation to obtain a compact and low dimensional face representation. Small kernel sizes of convolution layers, Network in Network layers and Residual Blocks have been implemented to reduce parameter space and improve performance. And for isolation failure [22] approach by embedded system (GPS \& GSM Asset Tracker) to provide an alternative solution to know vehicle location in case has been stolen, this asset tracker module from Particle IO [23] is also suitable to create smart padlock prototype (See Fig. 5).

What will happened? This issue was a common problem throughout the plant, that issuer and receiver failed to comply with procedure, and there is no system to monitor or control this behavior. At a later stage, there is a high chance that similar problem will rise.

What should I do? Generally, the manual PTW is to be enhanced with ePTW in a way to give decision support for the user, this can be achieved by taking advantage of IoT features on mobile phone, e.g. camera can be use as face recognition to verify the issuer and receiver authority, then use the GPS to verify that the stakeholder is onsite to do risk/hazard assessment.

Another approach on decision automation is to have hazard and precaution repository using ePTW established data that could provide issuer and receiver key word of proper hazard risk assessment on the system, that will enable to assist the worker on how to control or have a precaution on define hazard. By using [24] Fuzzy Bag-of-Words (FBoW) method the system able to adopts a fuzzy mapping based on the semantic correlation among words quantified by cosine similarity measures between word embeddings. Since word semantic matching instead of exact word string matching is used, the FBoW could encode more semantics into the numerical representation, e.g., user feed the hazard identification form with "Tripping by pavement" than on corrective action precaution form, computer will suggest the user to "aware surrounding, Paint the pavement, housekeeping, etc." it will give clear suggestion to user what is the preventive action to be taken, all these machine learning methods could really help the user to define the correct hazard identification for specific job.

Published By:

Blue Eyes Intelligence Engineering

\& Sciences Publication

(C) Copyright: All rights reserved.

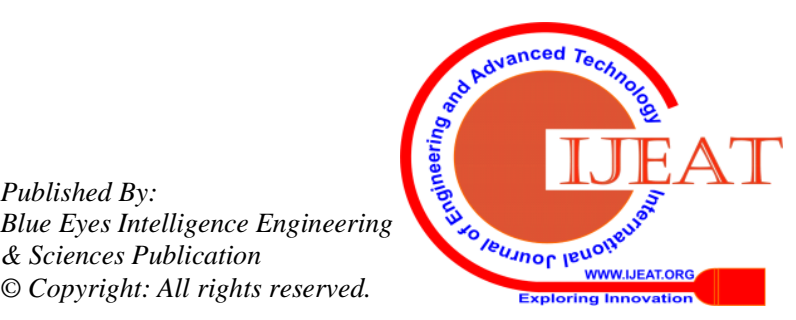




\section{Enhancement of Permit-to-Work System Toward Safety Risk Assessment Supporting by GPS, Face Recognition and IoT:Research on Company XYZ}

And embedded JSP (Job Safety Practice) related to the equipment or work setup, to predefined risk/hazard assessment on ePTW automatically.

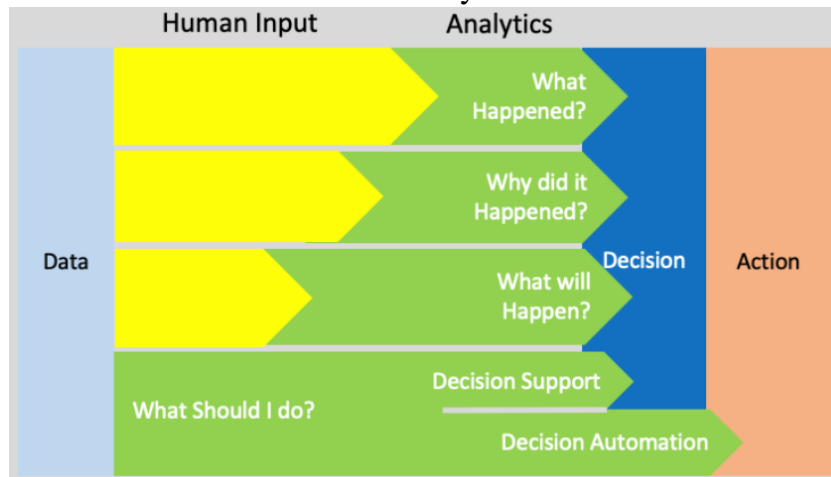

Fig.3. Analytic Maturity Assessment Model

\section{PROPOSED METHODS}

Under the suggested framework, ePTW Process Flow Chart is created as shown in Fig.4, The first step "Preparation" the receiver is to be recognized, then explain the work description, any associate equipment involves, attached (doc, pdf, etc.) if any related JSP to the system. Notify the issuer for the ePTW work plan to issue and in the background GPS location is recorded. Than review ePTW, by recognizing the issuer if succeed than input the requirement such as; timing, hours, validation/shift, the location of the work being done, work order number, and if the ePTW required extension / continuous work for more than one day, required another permit, etc. In the background, GPS location is recorded.

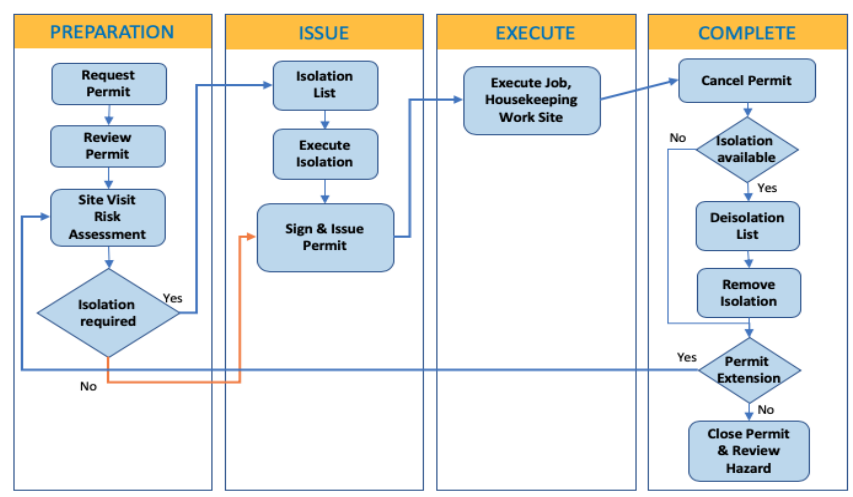

Fig.4. Process Flow Chart

Moreover, both (issuer \& receiver) visit the site to do risk assessment, to make sure that the recorded person is the one conducting the risk assessment, they have to validate by face recognition using convolutional neural network (CNN) algorithm and confirm by fiducial marker location [19] as well GPS location on the background.

The Second, if required isolation than lock out tag out (LOTO) sensor (See Fig. 5) will be added in a way to make sure that the worker is doing the job as per procedure. The worker could generate LOTO list to prevent others to unlock the smart pad lock or manual pad lock. After everything settle as per the procedure and risk assessment the permit can be issue and worker could start they work.

The fourth step, if the jobs were not done and required extension than they have to repeat the first step to visit the site and conduct the risk assessment and so on, however if the jobs have completed and they have cleared or normalize all related isolation and test the normal function than its required to input post hazard evaluation for future endeavor by receiver, so the ePTW can be close by issuer.

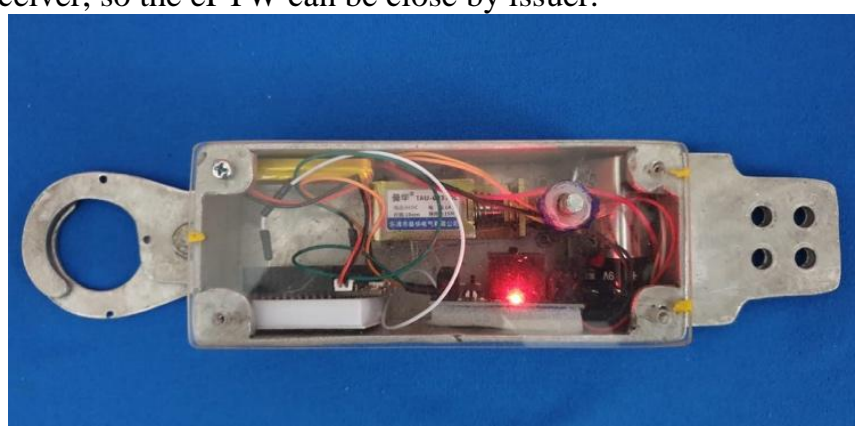

Fig.5. Smart LOTO Prototype

Moreover, ePTW Cloud computing application model is introduced to enabled for ubiquitous cozy, on-demand network access to computing resources, which can be released and added quickly [25]. The user does not need knowledge, expertise, or control over the cloud computing infrastructure [26]. As shown in Fig.6. the system will be using service-oriented architecture that breakdown the user services into small services, such as ePTW request, ePTW issue, Risk Assessment and Face Recognition. The common services are to support the user services by providing the support data (hazard dataset, Training record, etc.) and ePTW management.

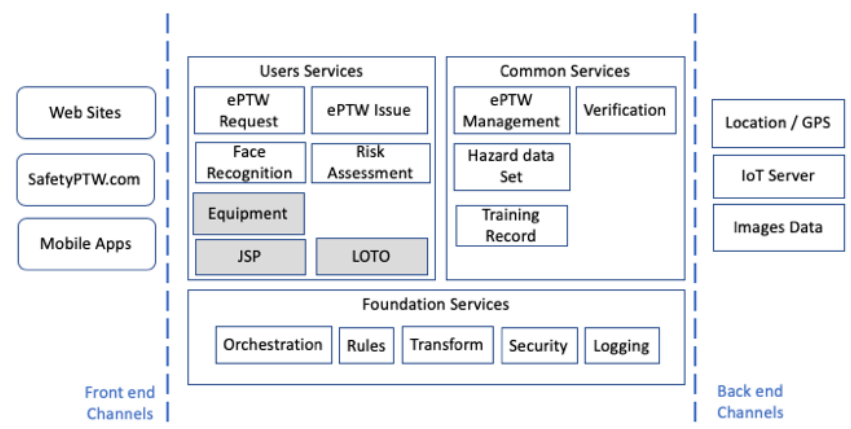

Fig. 6. ePTW Services Architecture

To determine the successful of this research, mobile maturity model [15] which are divided into mobile void, mobile aware, mobile enabled and mobile enterprise. As per the evaluation of current PTW system falls under mobile void, therefore the suggestion maturity model evaluation would be as per the following:

- Mobile Void: No mobile/system information exists (Current PTW).

- Mobile Aware: ePTW established in the form of mobile application. And current transaction (Create \& Issue PTW) is recorded.

- Mobile Enabled: Deviation related to PTW (Conduct risk/Hazard Assessment Onsite) is rectify, time taken to conduct PTW (before and after) is improved to boost the productivity and customer/user ePTW perception/ satisfactory are met.

\section{RESULT \& DISCUSSION}

As per the propose method of ePTW the results would be as per the following process: 
1. Established electronic form to fill all the PTW requirement as shown in Fig.7 the requester/receiver could easily create ePTW anytime and anywhere.

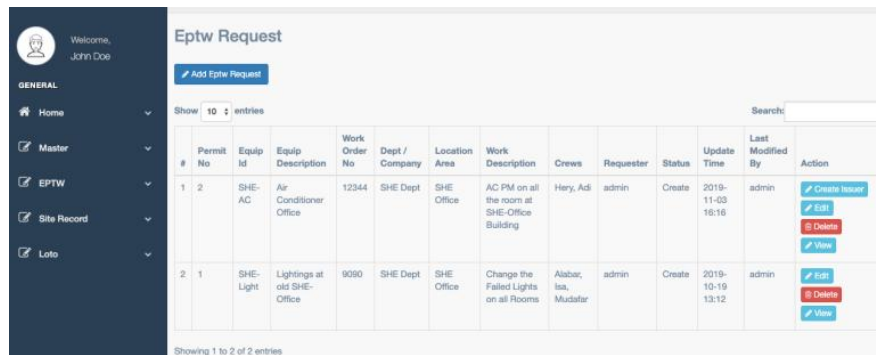

Fig.7. ePTW System Information

As shown in Fig.8 a survey audit on different categories are introduced to answer some of the problem in PTW system. This survey is conducted by 10 experiences employee both in safety and work with the following question:

- Is the PTW system compel the worker to do risk assessment onsite?

- Does the system prevent unauthorized people to alter the PTW?

- Does the system support hazard collection?

- Does the PTW has consistent record and easy to find?

- Does the system effective as hazard precaution?

- Does the system provide embedded JSP?

- Does the system effectively show LOTO notification?

- Does the system support multi equipment hazard evaluation?

- How long required to create PTW (minute)?

- How long required to close PTW (minute)?

The survey answer is using value range from 1 to 5 , which 1 $=$ Totally Dis-Agree and 5 = Totally Agreed.

Based on performance survey comparation between the current PTW with ePTW, it shows that the ePTW had higher score feedback from user in all assessment terms.

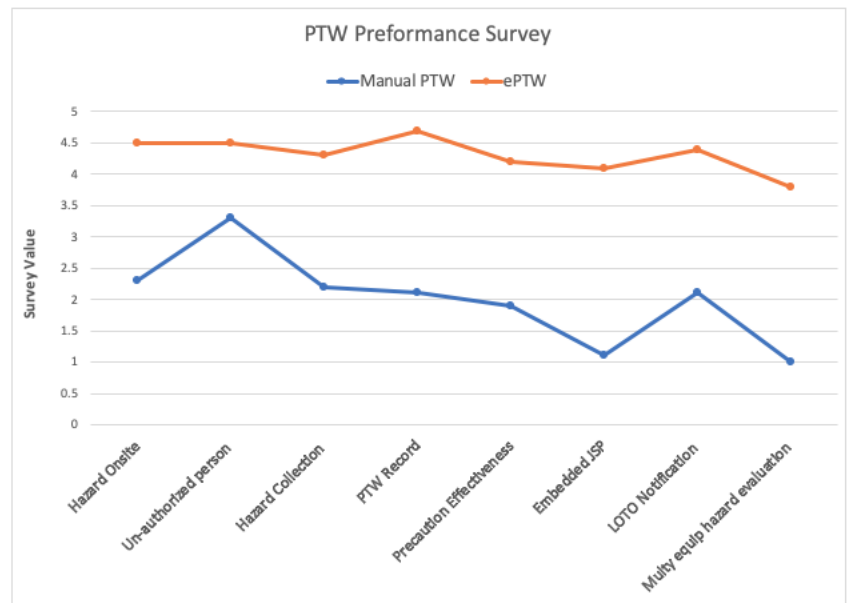

Fig.8. PTW Performance Survey

As shown in Fig.9 from ten correspondent the ePTW make the time taken to create or completed the PTW is dramatically improved, which boost the worker productivity and more efficient. This happened because the ePTW you can access it from any device and anywhere so the requester could create the ePTW request before they meet up with issuer, not like the conventional one they have to collect the form than fill it than again search the issuer, if the issuer or the form not available than its create un-necessary hustle and wasting of time.

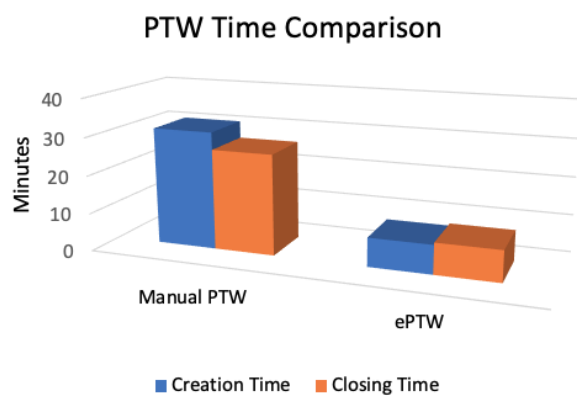

Fig.9. PTW Time Comparison

2. Another result as shown in Fig.10 is a way to solve the procedure deviation result, by make sure the worker doing the risk assessment onsite, face recognition to verify the identity and capture the GPS Location is introduced, and it had create a reliable system to prevent worker from deviate from the procedure which increase the compliance and increase safety culture by prevent worker to take short cut and direct them to do the task as per procedure.

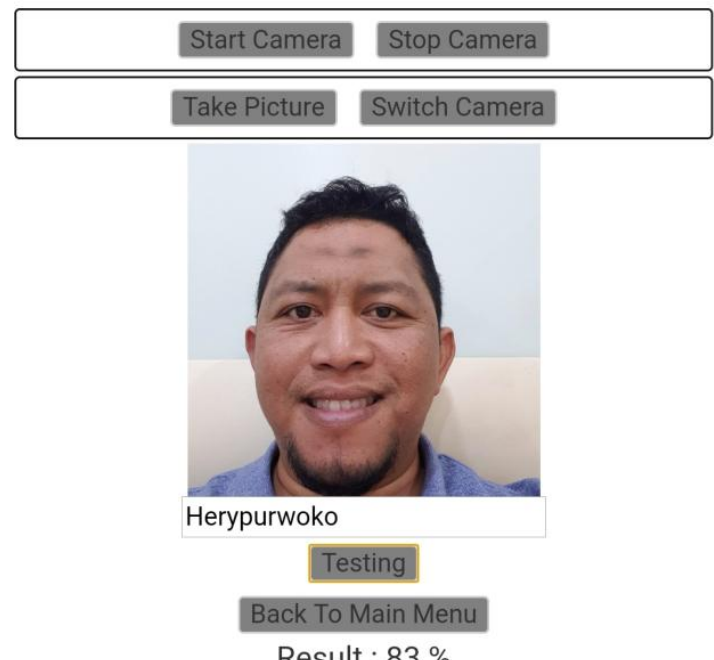

Fig.10. Face Recognition Verification

3. Moreover, the deviation result on preventing equipment from running whilst the worker doing the works by smart LOTO, as shown in Fig.11 the performance IoT (GSM \& WIFI) within different location and network connection (handshake) on location $\mathrm{H}$ and location I had blank spot which should be rectify by providing reliable WIFI connection on that area or using WIF IoT. The WIFI IoT have proven reliable on network connection and receive command from the application. The response time a lot faster than the GSM IoT, also there is a gap related to procedure and safety principal, that the GSM could remotely unlock the smart LOTO from distance its mean that the worker might not present on the premises to unlock the device which could increase potential hazard.

Published By:

Blue Eyes Intelligence Engineering \& Sciences Publication

(C) Copyright: All rights reserved.

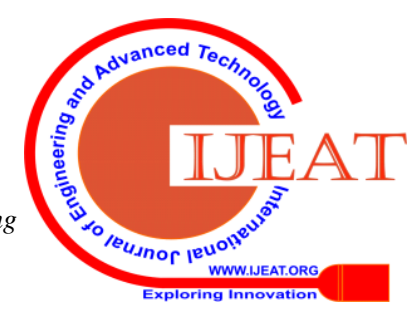




\section{Enhancement of Permit-to-Work System Toward Safety Risk Assessment Supporting by GPS, Face Recognition and IoT:Research on Company XYZ}

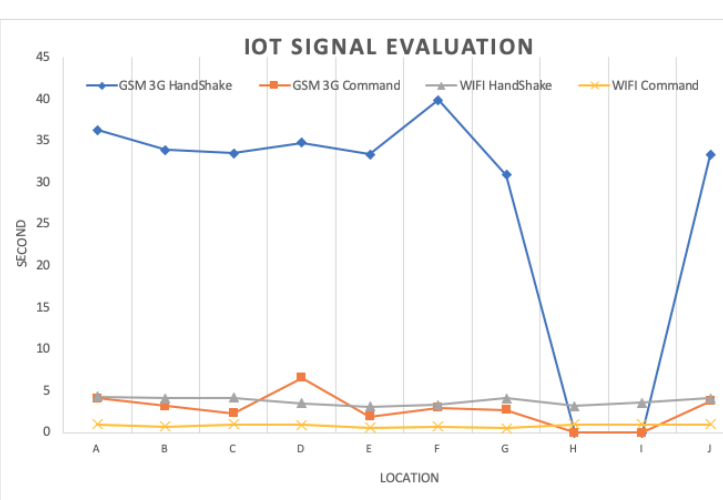

Fig.11. IoT Signal Evaluation

\section{CONCLUSION \& FUTURE WORKS}

This paper provide insight on how to enhance the PTW by using information technology to create electronic permit to work system (ePTW) to solve the deviation within PTW such as the creation of hazard risk assessment by using references from hazard dataset and available JSP for particular equipment which give the worker overview of safety precaution before doing their job in particular equipment or premises. And also, ePTW make sure both worker (Receiver and Issuer) are in the job premises to do risk assessment and to see the real condition on the job site and prevent the worker to cuts corner by using face recognition as identification and GPS location. Moreover, if the job required isolation, the Smart LOTO (IoT WIFI) could be used for many workers on different section and it not required each of the worker/section to provide padlock, just add lock on LOTO list on particular equipment to avoid other worker/section to unlock the Smart LOTO.

It is inevitable that the current system had lack in many areas such as onsite hazard risk assessment, Embedded JSP, etc. and the performance of PTW system had exceeded maturity evaluation level, from mobile void to mobile enabled and base on that the research has finally reach the objective.

Even though most of research area on PTW have been covered however for the future works the ePTW information system required is to be integrated with other system that could become enterprise solution and also the system required to be developed on other platform such as IOS, also on ePTW there's should be a sentiment analysis to analyze rather the ePTW had better acceptance and method statement in a way to develop more reliable and efficient ePTW in future endeavors.

\section{ACKNOWLEDGMENT}

This research was supported by company XYZ. We thank our colleagues from many departments at company XYZ whom provided insight and expertise that greatly assisted the research of PTW, also my fellow colleagues at Bina Nusantara (Adi Saputra and Panji Martono).

\section{REFERENCES}

1. I. K. Yoon, J. M. Seo, N. Jang, S. K. Oh, D. Shin and E. S. Yoon, "A Practical Framework for Mandatory Job Safety Analysis Embedded in the Permit-to-Work System and Application to Gas Industry," Journal of Chemical Engineering of Japan, pp. 976-988, 2011. W.-K. Chen, Linear pp. 50-57, 2014
M. Jahangiri, N. Hoboubi, A. Rostamabadi and S. Keshavarzi, "Human Error Analysis in a Permit to Work System: A Case Study in a Chemical Plant," Safety and Health at Work 7 (2016) 6-11, pp. 6-11, 2016.

3. S. Zhang, F. Boukamp and J. Teizer, "Automation in Construction Ontology-based semantic modeling of construction safety knowledge Towards automated safety planning for job hazard analysis ( JHA )," Automation in Construction, vol. 52, pp. 29-41, 2015.

4. SHE Dept., "Company XYZ Safety Management System," Askar, 2017.

5. IOSH, Managing safely Ver. 5.0, IOSH, 2018.

6. LabourLaw, "Bahrain Occupational Health and Safety Law," 2017. [Online].Available:http://www.stc-bahrain.com/images/BahLabourLaw .pdf.

7. M. Pillay and M. Tuck, "Permit-to-Work Systems as a Health and Safety Risk Control Strategy in Mining : A Prospective Study in Resilience Engineering," Advances in Human Error, Reliability, Resilience, and Performance, Advances in Intelligent Systems and Computing , vol. 1 no. 589, pp. 145-154, 2018.

8. A. Rahmatulloh, G. E. Kusuma and W. Arninputranto, "Pembuatan Sistem Informasi Manajemen Work Permit Berbasis Aplikasi Website Surabaya, 2018.

9. F. N. B. Abu Bakar, "Assessment of Permit-To-Work (PTW) System in a Pipeline Operator Company," University of Malaya, Kualalumpur, 2017.

10. C. Koy, P. Han, K. Kidam and M. Wijayanuddin, "Contribution of Permit to Work to Process Safety Accident in the Chemical Process Industry," Chemical Engineering Transactions, pp. 883-888, 2017.

11. B. H. W. Hadikusumo and S. Rowlinson, "Capturing Safety Knowledge Using Design-for-Safety-Process Tool," JOURNAL OF CONSTRUCTION ENGINEERING AND MANAGEMENT, Vols. 2004.130:281-289, pp. 281-289, 2004.

12. M. Swallow and S. Zulu, "Benefits and Barriers to the Adoption of 4D Modeling for Site Health and Safety Management," vol. 4, no. January, pp. 1-11, 2019.

13. Z. Chen, Z. Li and C. Huang, "Safety Assesment Methode of Bridge Crane Based on Cluster Analysis and Neural Network," in 8th (ICICT-2018) , Hangzhou, 2018

14. D. Proença and J. Borbinha, "Maturity Models for Information Systems - A State of the Art," Procedia Computer Science, pp. 1042-1049, 2016 Alqahtani and A. S. Atkins, "Mobile Maturity Models for Mobil Transformation," Procedia - Procedia Computer Science, vol. 83, no. Fams, pp. 1070-1077, 2016.

16. J. Hagerty, "2017 Planning Guide for Data and Analytics," Gartner-Technical Professional Advice, pp. 1-27, 13102016.

17. B. Soewito, F. L. Gaol, E. Simanjuntak and F. E. Gunawan, "Smart Mobile Attendance System Using Voice Recognition and Fingerprint on Smartphone," 2016 International Seminar on Intelligent Technology and Its Application, pp. 175-180, 2016.

18. W. Yuan, P. Deng and C. Yang, "A Smart Work Performance Measurement System for Police Officers," SPECIAL SECTION ON CHALLENGES FOR SMART WORLDS, pp. 1755-1764, 2015.

19. C. Barberis, A. Bottino and G. Malnati, "Indoor Navigation on Mobile Devices Sensing Signals for Indoor Positioning," Mobile Computing,

20. G. P. Kusuma and C.-S. Chua, "PCA-based image recombination for multimodal 2D+3D face recognition," Image and Vision Computing, pp. 306-316, 2011.

X. Wu, R. He, Z. Sun and T. Tan, "A Light CNN for Deep Face No.8, August 2017, pp. 1-13, 2017. accelerometer sensor system in Jakarta," Internetworking Indonesia Journal, pp. 9-15, 2017.

23. T. G. Ferrari and J. Bowen, "An IoT for Everyone : Fact or Fiction ?," in BCS Learning and Development Ltd., Belfast, UK, 2018.

24. R. Zhao and K. Mao, "Fuzzy Bag-of-Words Model for Document," Journal of Latex Class Files IEEE Vol 14, No.8, 2017.

25. J. Tandy and S. , "Cloud Computing dan Dampaknya Terhadap Bisnis," Cloud Computing, pp. 687-695, 2013.

26. D. Debashis, Mobile Cloud Computing: architecture, algorithms and application., CRC Press, 2016.

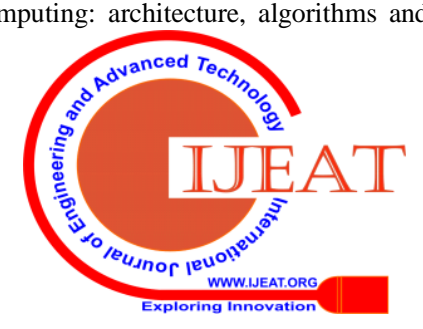




\section{AUTHORS PROFILE}

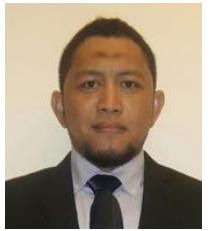

Hery Purwoko, received B.Sc. degree in Technical Information Engineering from University Persada Indonesia (UPI) YAI. Jakarta, Indonesia in 2002. He is currently pursuing a master's degree in Bina Nusantara University, Indonesia.

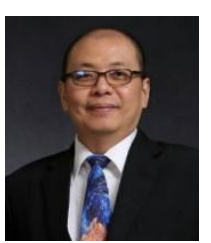

Suryadiputra Liawatimena, received a B.Sc degree in Computer Engineering from STMIK Bina Nusantara, Jakarta, Indonesia, in 1991, a master's degree in Computer Studies (Applied Science) from Edith Cowan University, Perth, Western Australia, in 1996, and a doctoral degree in Science Education from Curtin University, Perth, Western Australia, in 2005. His current area of research includes Computer Vision, embedded Linux applications, embedded systems, Internet of Things, weather data collection and prediction, and Radio Frequency Identification and Near Field Communications Applications. $\mathrm{He}$ is currently a senior lecturer at the Computer Engineering Department and Information Technology Master's Degree and the Bee Embedded Research Interest Group Leader at Bina Nusantara University.

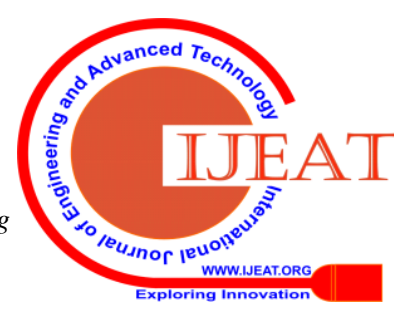

